\title{
ARBITRAGEM E A JUSTIÇA: PASSAGEM DA JUSTIÇA ARISTOTÉLICA PARA A JUSTIÇA KANTIANA
}

Filipe Augusto Piazza ${ }^{1}$

\section{RESUMO}

No advento da nova lei de arbitragem brasileira em 1996, é levantada a possibilidade de visualizarmos a aplicação do conceito da justiça kantiana, que é baseado na liberdade, no lugar da justiça aristotélica, que é fundada na igualdade originada da lei posta. Será realmente possível pensarmos num julgamento no qual o julgador pode adentrar além da relação jurídica para ele colocada, a fim de visualizar as reais situações das partes, das suas intenções ao pactuar, e as razões que geraram o conflito, para julgar no sentido de possibilitar a garantia e o desenvolvimento da personalidade dessas?

\section{ABSTRACT}

In the advent of a new arbitration's law in 1996, the possibility of seeing the application of kant's justice concept, which is based on liberty, in place of the Aristotle's justice passageway, which is founded in equality originated from the put law, is raised. Will it really be possible for us to think of a judgment in which the judge can go beyond the legal relation placed before him and visualize the real situation of the parts, their intentions while submitting to a contract, and the reasons that generate the conflict, to judge in the sense of ensuring the guarantee and the personality's development of the parts?

PALAVRAS CHAVES: ARBITRAGEM- JUSTIÇA- KANT.

KEY WORDS: ARBITRATION - JUSTICE -KANT.

\footnotetext{
${ }^{1}$ Bacharel em Direito pela Universidade Federal do Paraná, cursando a Especialização em Direito Tributário pelo IBET - Instituto Brasileiro de Estudos Tributários, como também, cursando Ciências Contábeis pela Universidade Federal do Paraná.
}

Revista Brasileira de Direito Internacional, Curitiba, v.2, n.2, jul./dez.2005 


\section{INTRODUÇÃO}

Justiça. Não seria ela um objetivo fundamental do Estado brasileiro²? Não seria para alcançá-la que tentamos construir um sistema jurídico sem contradições e paradoxos?

É fácil visualizarmos que a justiça detém um lugar fundamental em nossas vidas como cidadãos, pois somos nós que elegemos os governantes desse país, que tem o dever de construir uma sociedade justa; e como operadores do direito, pois esse deve necessariamente ser um instrumento para alcançar a justiça no caso concreto.

Por vezes nos deparamos com debates a respeito do conteúdo de uma determinada lei, tendo essa a finalidade primeira de instituir sobre a sociedade, a justiça, mesmo quando não sabemos ao certo o que é a justiça. Ou seja, não sabemos ao certo o que é realmente a justiça, mas sempre estamos prontos a discutir idéias, leis e regulamentos a fim de alcançá-la.

Sabemos que através de breves palavras que aqui serão ditas, não poderemos dissecar todos os elementos e minúcias que a definição de justiça pode suscitar. Não é esse nosso objetivo.

O que nos propomos a realizar é alguns comentários sobre a justiça aristotélica, justiça que funda nosso sistema legal, e sobre a justiça kantiana, que tem seu fundamento na liberdade, e que busca garantir que o ser humano tenha a possibilidade de expressar ao máximo sua própria personalidade, pois temos conviçcão que o debate desses dois modos de se pensar e de definir a justiça trarão fundamentos básicos que evidenciaram a importância da discussão da justiça, especialmente aquela alcançada através do direito.

Visualizamos no instituto da arbitragem, que através da promulgação da lei 9.307 de 1996, ganhou a atualização necessária para adequar o país, ao costume internacional de solução de conflitos através de árbitros, sem o uso do Poder Judiciário, e especialmente na arbitragem por equidade, um meio de

\footnotetext{
${ }^{2}$ Constituição Federal de 1988. Art. 3-- Constituem objetivos fundamentais da República Federativa do Brasil:

I - construir uma sociedade livre, justa e solidária;
}

Revista Brasileira de Direito Internacional, Curitiba, v.2, n.2, jul./dez.2005 
realizarmos uma mudança no conceito de justiça aplicada no caso concreto, através da passagem da justiça aristotélica para a justiça kantiana.

Começaremos por apresentar breves comentários sobre a arbitragem, passando à definição e alguns comentários da justiça aristotélica e da justiça kantiana, finalizando com a passagem da justiça aristotélica para a kantiana através da arbitragem.

\section{A ARBITRAGEM}

Com o advento da nova lei 9.307 de 23 de setembro de 1996, que regula sobre a arbitragem, renova-se no Brasil o instituto processual do juízo arbitral, como via alternativa de resolução de conflito, que antes da nova codificação estava disposto no Código de Processo Civil, nos artigos 1.072 ao 1.102.

A arbitragem é um meio extrajudicial de resolução de conflito de interesses qualificado pelo direito, na qual é escolhido um terceiro denominado árbitro, para emitir um juízo de valor sobre a controvérsia em relação a direitos transigíveis ${ }^{3}$ a ele apresentado.

Já CARREIRA ALVIM, em seu livro DIREITO ARBITRAL, assim conceitua arbitragem como sendo "a instituição pela qual as pessoas capazes de contratar confiam a árbitros, por elas indicados ou não, o julgamento de seus litígios relativos a direitos transigíveis". 4

O árbitro, agente julgador da lide arbitral, terá de ser pessoa que detém a confiança das partes, segundo afirma o artigo $13^{5}$ da Lei de Arbitragem,

\footnotetext{
${ }^{3}$ Estamos usando com intuito de conceituação o termo "direitos transigíveis" a relação ao entendimento à legislação alemã, italiana e argentina que assim classificam a arbitragem.

${ }_{5}^{4}$ ALVIM, J. E. Carreira. Direito Arbitra. RJ: Forense, 2004 pág. 1

${ }^{5}$ Lei 9.307/1996 Art. 13. Pode ser árbitro qualquer pessoa capaz e que tenha a confiança das partes.

$\S 1^{\circ}$. As partes nomearão um ou mais árbitros, sempre em número ímpar, podendo nomear, também, os respectivos suplentes.

$\S 2$. Quando as partes nomearem árbitros em número par, estes estão autorizados, desde logo, a nomear mais um árbitro. Não havendo acordo, requererão as partes ao órgão do Poder Judiciário a que tocaria, originariamente, o julgamento da causa a nomeação do árbitro, aplicável, no que couber, o procedimento previsto no artigo $7^{\circ}$ desta Lei.

$\S 3^{\circ}$. As partes poderão, de comum acordo, estabelecer o processo de escolha dos árbitros, ou adotar as regras de um órgão arbitral institucional ou entidade especializada.
}

Revista Brasileira de Direito Internacional, Curitiba, v.2, n.2, jul./dez.2005 
detendo a decisão proferida por ele efeito de sentença, não sendo essa sujeita a recurso ou homologação pelo Poder Judiciário. Ou seja, é delegado ao árbitro, por intermédio das partes, o poder de ser juiz de fato e de direito na lide arbitral, como afirma o artigo $18^{6}$ da Lei de Arbitragem.

O que mostra notório no artigo $2^{{ }^{07}}$ da Lei de arbitragem atual é o fato de a lei conceder às partes o direito de eleger o modo pelo qual querem ter 0 litígio julgado.

Podem as partes optar pela arbitragem de direito e de equidade, escolhendo livremente as regras de direito, desde que não haja violação aos bons costumes e à ordem pública, sendo possível convencionar que a arbitragem se realize com base nos princípios gerais de direito, nos usos e costumes e nas regras internacionais de comércio.

Sobre a arbitragem por equidade, afirma Carlos Alberto Carmona:

\begin{abstract}
"Em outros termos, sendo a norma abstrata, criada para reger fatos-tipos, pode acontecer que em dado caso concreto ocorra circunstância que o legislador não previsto, tornando a incidência da norma injusta e inadequada. É nesta hipótese que atuaria a equidade, autorizando o legislador a mitigar a severidade da norma. Assim, quando autorizado a julgar por equidade, o julgador pode com largueza eleger as situações em que a norma não merece mais aplicação, ou porque a situação não foi prevista pelo legislador, ou porque a norma envelheceu e não acompanhou a realidade, ou porque a aplicação da norma causará injusto desequilíbrio entre as partes (...)".8
\end{abstract}

Assim pode o árbitro, quando a ele conferido o poder para julgar por equidade, decidir conforme o direito positivo, ou decidir no sentido contrário à

$\S 4$. Sendo nomeados vários árbitros, estes, por maioria, elegerão o presidente do tribunal arbitral. Não havendo consenso, será designado presidente o mais idoso.

$\S 5$ ‥ O árbitro ou o presidente do tribunal designará, se julgar conveniente, um secretário, que poderá ser um dos árbitros.

$\S 60$. No desempenho de sua função, o árbitro deverá proceder com imparcialidade, independência, competência, diligência e discrição.

$\S 77^{\circ}$. Poderá o árbitro ou o tribunal arbitral determinar às partes o adiantamento de verbas para despesas e diligências que julgar necessárias.

${ }^{6}$ Lei 9.307/1996 Art. 18. O árbitro é juiz de fato e de direito, e a sentença que proferir não fica sujeita a recurso ou a homologação pelo Poder Judiciário.

${ }^{7}$ Lei 9.307/1996 Art. 2‥ A arbitragem poderá ser de direito ou de eqüidade, a critério das partes.

$\S 1$. Poderão as partes escolher, livremente, as regras de direito que serão aplicadas na arbitragem, desde que não haja violação aos bons costumes e à ordem pública.

$\S 2$. . Poderão, também, as partes convencionar que a arbitragem se realize com base nos princípios gerais de direito, nos usos e costumes e nas regras internacionais de comércio.

${ }^{8}$ CARMONA, Carlos Alberto, Arbitragem e Processo - Um Comentário à Lei no 9.307/96, 2a

Edição Revista, Atualizada e Ampliada, Editora Atlas S.A. - São Paulo, 2004. Pág. 76

Revista Brasileira de Direito Internacional, Curitiba, v.2, n.2, jul./dez.2005 
lei posta. Ou seja, fica a critério do árbitro averiguar onde se achará a justiça no caso concreto: se na lei positivada, ou fora dela. Nesse sentido, Carmona conclui que "Em outros termos, se a aplicação da norma levar a uma solução justa do conflito, o árbitro a aplicará, sem que isto possa ensejar qualquer vício no julgamento". 9

Limitando o julgamento por equidade, a própria lei de arbitragem enuncia que não pode essa violar os bons costumes e à ordem pública.

Afirma J. E. Carreira Alvim, que o julgamento por equidade não pode ser sustentado somente em valores intelectuais (equidade cerebrina), mas deve ser "identificada pelo julgador nos valores consagrados pelo ordenamento jurídico". ${ }^{10}$ Observa ainda, citando Fazzalari, que a ordem pública pode ser considerada como "síntese dos valores fundamentais do ordenamento jurídico (...)". ${ }^{11}$

Dito isso, dentro da possibilidade das partes elegerem a equidade como modo de julgamento pelo arbitro da lide arbitral, mesmo precisando limitar pelos bons costumes e à ordem pública, emerge a possibilidade então na arbitragem por equidade do aparecimento de decisões com fundamento na justiça como liberdade de Kant, pois o árbitro não fica mais preso a obrigação empregar a lei posta, mas pode escolher aplicá-la, como adiante será mostrada.

\section{A JUSTIÇA ARISTOTÉLICA}

Adentrando na definição da justiça aristotélica, podemos observar que essa se encontra nos fundamentos do direito moderno, e que nosso tradicional conceito de justiça advém da forma como Aristóteles o pensou.

Para Aristóteles a justiça era uma virtude, e por ser uma virtude, era caracterizado em sendo um justo meio (mesótes) ${ }^{12}$.

\footnotetext{
${ }^{9}$ CARMONA, Carlos Alberto, Idem, pág 77

${ }^{10}$ ALVIM, J. E. Carreira; Obra citada, pág. 163

${ }^{11}$ ALVIM, J.E. C., Idem pág. 163

12 BITTAR, Eduardo C.B. Teorias sobre a Justiça; Apontamentos para a História da

Filosofia do Direito, São Paulo: Editora Juarez de Oliveira, 2000. Pág. 37
}

Revista Brasileira de Direito Internacional, Curitiba, v.2, n.2, jul./dez.2005 
Como um justo meio, caracteriza-se por se encontrar na média aritmética de dois extremos, a carência e o excesso, sendo esses extremos adjetivos do termo injustiça, ou seja, é uma virtude que se contrapõem com um vício, e não com dois diferentes. Eduardo Bittar assim observa com clareza:

\footnotetext{
"A justiça, em meio a demais virtudes, que se opõem a dois extremos (um por carência: temeroso; outro por excesso: destemido), se caracteriza por uma peculiaridade: trata-se de uma virtude à qual não se opõem dois vícios diferentes, mas um único vício, que é a injustiça (um por carência: injusto por carência; outro por excesso: injusto por excesso). Desta forma, o que é injusto ocupa dois pólos diversos, ou seja, é ora injustiça por excesso, ora injustiça por defeito". ${ }^{13}$
}

A justiça, em sua categorização genérica, acima exposta, é encontrada no equilíbrio situado numa posição mediana, entre dois pólos, caracterizando a igualdade, proporcional ou até mesmo absoluta.

Como podemos atribuir à justiça inúmeros sentidos, Aristóteles iniciou um exame sobre a noção da justiça total (díkaion nomimón ${ }^{14}$ ), que se caracterizou pela observância à lei.

Ele concluiu assim, pois entendeu que a lei é uma norma geral sobre a sociedade e que tem como fim o Bem da comunidade, ou seja, o Bem comum. Assim, respeitando e observando o conteúdo da lei, ficaria caracterizada a justiça no proceder.

Sobre a Justiça Total, assim afirma Bittar que "O justo total é a observância do que a regra social de caráter vinculativo. O hábito humano de conformar as ações ao conteúdo da lei é a própria realização da justiça nesta acepção (justiça total); justiça e legalidade são uma e a mesma coisa, nesta acepção do termo. Este tipo de prática causa efeitos altruístas, de acordo com a virtude total". 15

Neste sentido, a justiça como igualdade é explicada de modo claro por Noberto Bobbio:

"Segundo esta concepção, que é a mais antiga e tradicional (deriva de Aristóteles na sua formulação mais clara) o fim do direito, ou seja, das regras

\footnotetext{
${ }^{13}$ BITTAR, Eduardo C.B, Idem, Pág. 38

${ }^{14}$ BITTAR, Eduardo C.B, Idem, Pág. 39

${ }^{15}$ BITTAR, Eduardo C.B, Idem, Pág. 41
}

Revista Brasileira de Direito Internacional, Curitiba, v.2, n.2, jul./dez.2005 
coercitivas que disciplinam a conduta dos homens na sociedade, é de garantir a igualdade, seja nas relações entre os indivíduos (...) seja nas relações entre o Estado e os indivíduos (...) O direito é aqui o remédio primeiro e fundamental para as disparidades entre os homens, que podem derivar, seja das desigualdades naturais, seja das desigualdades sociais". ${ }^{16}$

Deste modo, podemos afirmar que fica caracterizada a justiça aristotélica como a justiça por igualdade obediente à lei. Ou seja, a definição de justo e injusto sobre uma pessoa ou um grupo de pessoas, ficará evidenciada na igualdade que a lei conferir a essa pessoa ou grupo delas.

Mostra-se claro que a justiça como enunciada por Aristóteles tem como fundamento um equilíbrio entre os direitos e privilégios que as pessoas detêm, sendo que esse equilíbrio é revelado através da lei.

Afirma John Rawls, em seu conceito de justiça, esse fundado no conceito de Aristóteles:

\begin{abstract}
"Nessas observações preliminares fiz uma distinção entre o conceito de justiça significando um equilíbrio adequado entre reivindicações concorrentes e uma concepção da justiça como um conjunto de princípios correlacionados com a identificação das causas principais que determinam esse equilíbrio".

(...)

"Considero por conseguinte que o conceito de justiça se define pela atuação de seus princípios na atribuição de direito e deveres e na definição da divisão apropriada de vantagens sociais. Uma concepção de justiça é uma interpretação dessa atuação".

(...)

"O sentido mais específico que Aristóteles atribui à justiça, e do qual derivam as formulações mais conhecidas da justiça, é o de evitar a pleonexia, isto é, evitar que se tire alguma vantagem em benefício próprio tomando o que pertence a outrem, sua propriedade, sua recompensa a alguém o que lhe é devido,(...)" ${ }^{17}$
\end{abstract}

É classificado, portanto, como injustiça uma pessoa deter mais direitos e privilégios que outra, estando elas em iguais capacidades jurídicas ${ }^{18}$ e sob a autoridade da mesma lei.

Sendo assim, fica manifesto a necessidade da lei classificar as pessoas da maneira mais objetiva possível, diferenciando as que têm

${ }^{16}$ BOBBIO, Norberto, Direito e Estado no Pensamento de Emanuel Kant, $3^{\text {a }}$ Edição, Brasília, Editora Universidade de Brasília, 1995. Pág. 72

${ }^{17}$ RAWLS, John , Uma teoria da justiça - São Paulo: Martins Fontes, 1997.Pág. 11

${ }^{18}$ É evidente que se encontrando uma pessoa em condições de incapacidade jurídica, como os excepcionais e os demais incapazes enunciados no artigo $4^{\circ}$ do Código Civil, deverá ela receber direitos e privilégios distintos daqueles classificados como capazes jurídicos.

Revista Brasileira de Direito Internacional, Curitiba, v.2, n.2, jul./dez.2005 
dificuldades de exercer suas capacidades jurídicas, não conseguindo, portanto, dar condições de receber as particularidades que cada indivíduo detém em sua existência.

Tem assim, a justiça aristotélica a característica de enquadrar a pessoa em um sistema dicotômico entre justo e injusto, não conseguindo adentrar dentro da real condição humana que vive essa pessoa como também na relação jurídica que essa faz parte, sendo essa forma de justiça parcial e incompleta, pois usa a lei para chegar a pessoa, não permitindo que a pessoa chegue ao status de justiça através simplesmente do que ela subjetivamente é, mas sempre em relação à lei que a classifica.

\section{A JUSTIÇA KANTIANA}

O filósofo Emanuel Kant pensando a partir do direito de liberdade, construiu o conceito de justiça baseado em um direito que seria "o conjunto das condições, por meio das quais o arbítrio de um pode estar de acordo com o arbítrio de um outro segundo uma lei universal de liberdade", ${ }^{19}$ segundo afirma Bobbio citando Kant.

A característica mais marcante desse conceito de direito de Kant, conceito no qual se fundará a justiça, é que não diz respeito a simplesmente a uma maneira de coexistir, mas as condições de coexistir com os arbítrios dos outros.

Assim, a liberdade pessoal é limitada quando atinge a liberdade do outro, sendo que todos têm o direito de exercer a liberdade igual à daquele.

Ou seja, não é prescrito na lei como você deve agir, mas sim a sua liberdade de agir até o limite do outro. Assim, afirma Bobbio que: "De fato, podemos dizer que, segundo Kant, o direito é a forma universal de coexistência dos arbítrios dos simples. Enquanto tal é a condição ou o conjunto das condições segundo as quais os homens podem conviver entre si, ou o limite da

\footnotetext{
${ }^{19}$ BOBBIO, Op. Cit. Pág. 70
}

Revista Brasileira de Direito Internacional, Curitiba, v.2, n.2, jul./dez.2005 
liberdade de cada um, de maneira que todas as liberdades externas possam coexistir segundo uma lei universal". ${ }^{20}$

Assim, o conceito de justiça de Kant é liberdade, ou seja, o "justo" seria alcançado quando o indivíduo tivesse a garantia de poder expressar de forma máxima a sua própria personalidade. O ordenamento jurídico precisa garantir, através de suas normas coercitivas, um espaço para cada indivíduo ser livre, e nessa liberdade desenvolver sua própria personalidade, não prejudicando a esfera de liberdade dos outros. Nesse sentido, Bobbio afirma, em seu livro sobre Kant:

\begin{abstract}
“A razão última pela qual os homens se reuniram em sociedade e constituíram o Estado, é a de garantir a expressão máxima da própria personalidade, que não seria possível se um conjunto de normas coercitivas não garantisse para cada um uma esfera de liberdade, impedindo a violação por parte dos outros. O ordenamento justo é somente aquele que consegue fazer com que todos os consociados possam usufruir uma esfera de liberdade tal que lhes seja consentido desenvolver a própria personalidade seguindo o talento peculiar de cada um". ${ }^{21}$
\end{abstract}

Podemos observar que a preocupação de Kant não é colocar a todos debaixo da mesma lei e assim que cada qual tenha os mesmos direitos e privilégios, como prescrevem os ensinamentos de Aristóteles, mas de conceder a todos a liberdade de desenvolver a sua própria personalidade ao máximo.

Fica evidente que a lei, em Kant, não precisará enunciar todos os direitos e privilégios que a pessoa deverá ter, mas deixará a cada um o direito de escolher, segundo a particularidade pessoal, quais serão os direitos que melhor garantiriam o desenvolvimento da personalidade, assegurando a lei, somente o direito a essa liberdade.

Sobre a função dos julgadores dentro desse conceito de justiça, podemos afirmar que esses terão o dever de remover qualquer obstáculo que impeça a fruição da liberdade pessoal que é lícito ser consentida pela liberdade igual à dos outros.

Colocado dessa forma, podemos afirmar que Kant modifica toda a maneira de analisarmos a lide processual como também as relações jurídicas,

\footnotetext{
${ }^{20}$ BOBBIO, Op. Cit. Pág. 71

${ }^{21}$ BOBBIO, Op. Cit. Pág 73
}

Revista Brasileira de Direito Internacional, Curitiba, v.2, n.2, jul./dez.2005 
pois o juiz pode se julgar visando à justiça kantiana, adentrar dentro da relação jurídica e averiguar quais são os reais elementos e razões que fundamentam a lide, e decidir em prol do desenvolvimento das pessoas ${ }^{22}$ ali envolvidas e não somente na solução do problema a luz do direito positivado vigente.

Ficará evidenciado no próximo tópico que a passagem de uma justiça aristotélica para a kantiana é possível na arbitragem, pois essa pode conceder ao árbitro, se assim escolher as partes, o poder de julgar além ou até mesmo contra legen, florescendo um campo propício para a análise mais apura da relação jurídica substancial dentro de uma lide processual.

Por hora, conclui Bobbio:

\begin{abstract}
"Portanto, não é suficiente, segundo o ideal do direito como liberdade, que o ordenamento jurídico estabeleça a ordem, nem é suficiente que esta ordem seja fundada na igualdade (também uma sociedade na qual todos sejam escravos é uma sociedade de iguais, ainda que iguais na escravidão). É necessário, para que brilhe a justiça com toda a sua luz, que os membros da associação usufruam da mais ampla liberdade compatível com a existência da própria associação. Motivo pelo qual seria justo somente aquele ordenamento em que fosse estabelecida uma ordem na liberdade“". ${ }^{23}$
\end{abstract}

\title{
5 PASSAGEM DA JUSTIÇA ARISTOTÉLICA PARA A KANTIANA ATRAVÉS DA ARBITRAGEM
}

Evidenciado os dois modos de justiça, faz-se necessário mostrar a passagem que queremos efetuar da justiça aristotélica para a kantiana através da arbitragem por equidade.

A justiça aristotélica detém o fundamento da lei como critério julgador do justo e injusto. $\mathrm{Na}$ arbitragem pode-se valer desse modo de julgamento, pois as partes podem escolher qual é ou quais são as leis que podem ser aplicadas no caso ao árbitro apresentado.

\footnotetext{
${ }^{22}$ Temos que observar que a lei brasileira não confere ao juiz esse poder discricionário de adentrar na relação jurídica dessa maneira. Uma exceção é a presença de uma lacuna na lei, caso em que o juiz decidirá de acordo com a analogia, os costumes e os princípios gerais do direito (artigo 4ํ da Lei de Introdução ao Código Civil - LICC). Ou seja, mesmo quando a lei não dispuser de norma que regulamenta um caso concreto, não pode o juiz alterar o modo de julgar, recaindo ainda sobre a justiça por equidade de Aristóteles, precisando ele usar regras e princípios do próprio ordenamento jurídico brasileiro no qual está inserido.

${ }^{23}$ BOBBIO, Op. Cit. Pág. 73
}

Revista Brasileira de Direito Internacional, Curitiba, v.2, n.2, jul./dez.2005 
Desse modo, podemos observar que esse deverá julgar de acordo com a lei escolhida.

Apesar de não ser impossível o árbitro julgar uma lide baseada em uma lei específica de um modo diferente da ótica aristotélica, mostra-se improvável tal feito, pois, geralmente, a vinculação a um sistema jurídico de um determinado país implica na vinculação ao modo de julgamento dos conflitos jurídicos, como é no caso brasileiro. ${ }^{24}$

Por outro lado, a justiça kantiana é fundada na liberdade e pressupõe um julgamento no qual o julgador poderá averiguar além da relação jurídica e adentrar dentro da situação real da parte, analisando suas reais possibilidades e condições de desenvolvimento.

A arbitragem pode usar esse modo de julgar, pois o árbitro, além de deter a confiança ${ }^{25}$ das partes, pode ser pessoa com um profundo conhecimento técnico sobre a matéria, sendo assim, mais fácil o árbitro compreender a situação que se encontram as partes e julgar no sentido de beneficiar o desenvolvimento econômico e social dessas.

Portanto, no nosso entender, faz-se permitido à arbitragem utilizar a concepção aristotélica de justiça para decidir a lide, mas também pode ela, se assim pactuarem as partes, fazer a passagem desse modo de julgamento, que é mais comum, para o julgamento fundado na justiça kantiana, que se preocupa no desenvolvimento pessoal das partes envolvidas na lide, podendo o árbitro "olhar" além da relação jurídica e lá encontrar a real situação das pessoas comprometidas no conflito.

\footnotetext{
${ }^{24} \mathrm{O}$ sistema jurídico brasileiro só aceita o julgamento por equidade no caso de lacuna no corpo do sistema. Mesmo nesse caso, o juiz deve resolver à situação usando primeiramente o método da analogia, que remete o fundamento da decisão a outra lei, fechando a possibilidade de outra interpretação. Só em últimos casos, quando faltam argumentos através da analogia, o juiz poderá usar os costumes e os princípios gerais do direito (artigo 4ํㅡㄹ Lei de Introdução ao Código Civil). Entendemos que no direito brasileiro, dificilmente um juiz usará esses dois últimos modos de julgamento, pois nossa Constituição detém princípios muito abertos, obstando o uso desses meios de interpretação e solução de controvérsia.

${ }^{25}$ A confiança é o pressuposto na qual a arbitragem é fundada, segundo o artigo 13 da Lei de Arbitragem. Podemos ainda afirmar que por deter a confiança das partes, o árbitro pode ser pessoa que já conheça a relação jurídica que deu causa a lide processual e já está ciente das intenções que as fizeram pactuar, como também os motivos pelos quais essa relação gerou um conflito social entre elas.
} 


\section{CONCLUSÃO}

Com a promulgação da nova lei de arbitragem brasileira, de número 9.307/1996, abriu-se, com a possibilidade do uso da arbitragem por equidade, uma porta que pode ser usada para a passagem da justiça aristotélica à justiça kantiana.

Uma passagem de uma justiça baseada na lei e em seus respectivos elementos puramente objetivos, que inúmeras vezes geraram injustiça no campo concreto da aplicação da lei, para uma justiça baseada na liberdade, e que visa o desenvolvimento da expressão da personalidade das pessoas imersas na sociedade.

Nos tempos atuais, quando ocorre um clamor social por justiça, fica evidenciada a importância do tema que acima colocamos.

Será que a utilização do modo kantiano de resolver os conflitos, enfocando a liberdade, e assim o desenvolvimento da personalidade como foco, não contribuirá para uma sociedade mais justa e solidária, como também para saciar o desejo de justiça que ronda os nossos dias?

Resposta a essa questão, o tempo poderá trazer...

\section{REFERÊNCIAS}

ALVIM, J. E. Carreira. Direito Arbitral. RJ: Forense, 2004.

BITTAR, Eduardo C.B. Teorias sobre a Justiça: Apontamentos para a

História da Filosofia do Direito. São Paulo: Editora Juarez de Oliveira, 2000.

BOBBIO, Norberto. Direito e Estado no Pensamento de Emanuel Kant. $3^{\text {a }}$ Edição, Brasília: Editora Universidade de Brasília, 1995.

CARMONA, Carlos Alberto. Arbitragem e Processo - Um Comentário à Lei no 9.307/96, 2ª Edição Revista, Atualizada e Ampliada. Editora Atlas S.A.: São Paulo, 2004.

RAWLS, John , Uma teoria da justiça; tradução Almiro Pisetta e Lenita M.R. Esteves - São Paulo: Martins Fontes, 1997. 